\title{
GIS-BASED ANALYSIS OF STORM VULNERABILITY CHANGE AT PEA ISLAND, NC
}

\author{
Eric Hardin ${ }^{1}$ Helena Mitasova² Margery Overton ${ }^{3}$
}

\begin{abstract}
In August 2011, Hurricane Irene opened multiple small breaches along the Outer Banks of North Carolina, USA. To predict storm damage to barrier islands, the United States Geological Survey (USGS) has developed the storm impact scale for barrier islands, which assesses vulnerability based on the configuration of the pre-storm terrain relative to storm characteristics. We present the vulnerability of Pea Island to Hurricane Isabel (2003) and Irene (2011) using an efficient GIS-based implementation of the storm impact scale. This implementation employs a least cost path approach to automated topographic feature extraction and a remote sensing approach to wrack line extraction for storm parameter estimation. The assessed vulnerability along with high-resolution topographic visualizations based on a decadal time-series of Light Detection and Ranging (LiDAR) data suggest that the location of the breach formation was a function of the pre-storm terrain. With the presented methodology, the geospatial information required to identify vulnerable areas can efficiently be extracted so that management strategies can be implemented before storm damage occurs.
\end{abstract}

Keywords: automated feature extraction; LiDAR; GRASS GIS; coastal dunes; barrier islands

\section{INTRODUCTION}

In August 2011, Hurricane Irene struck the coast of North Carolina. It traveled north through the sounds that separate North Carolina's mainland coast from the offshore barrier island system known as the Outer Banks (Figure 1). Irene's northward path and counter-clockwise rotation maximized storm surge along the sound-side of the Outer Banks as it passed.

Irene caused extensive damage to the barrier island system, most notably opening multiple small breaches. The largest (referred to as the Pea Island breach) is approximately $60 \mathrm{~m}$ wide and has remained open (Figure 2). The damage severed highway NC12, which is the only transportation corridor and as such, functions as the primary evacuation route. It also uniquely enables the magnitude of tourism that the region relies on. Consequently, keeping NC12 open is vital to the population that lives in the Outer Banks

There are six locations along the Outer Banks where NC12 has a long history of being rendered impassable due to storm damage and overwash deposits (Stone et al. 1991). These areas have become known as the "NC12 hotspots." One of the hotspots is located in the Pea Island National Wildlife Refuge (PINWR) and is the location of the Pea Island breach. The relationship between the characteristics of the pre-storm dune field, the storm conditions, and the post-storm geomorphology is the focus of this study.

To predict vulnerability to storm damage on the ocean side of a barrier island, the USGS has developed the storm impact scale for barrier islands (Sallenger et al. 2000). The storm impact scale categorizes beach-foredune topography as being vulnerable to one of four characteristically distinct erosion regimes, which are defined by the combined elevations of the tide, storm surge, and wave setup with and without runup relative to the elevations of the dune toe and crest. Similar conceptual models have been developed that also rely on topographic parameters extracted along a series of cross-shore beach profiles (e.g., Garcia-Mora et al. 2001, Hallermeier and Rhodes 2011, Jimenez et al. 2009, Jin and Overton 2011, Judge et al. 2003, Sallenger 2000, Stockdon et al. 2007, Stockdon and Thompson 2007a,b).

Computation of the storm impact scale requires elevations of the dune toe and dune crest. In this work, the dune toe and crest are extracted from Digital Elevation Models (DEM) using a novel least cost path approach (Hardin et al. 2012), as opposed to more traditional beach-profile methods. This approach estimates the location of the dune ridge as the least cost path on a cost surface, which is a function of the elevation surface.

The least cost path method is advantageous for a number of reasons. It is spatially distributed, which makes the method robust to topographic anomalies (e.g., houses or vegetation). It produces a

\footnotetext{
${ }^{1}$ Department of Physics, North Carolina State University, Campus Box 8202, Raleigh, NC, 27695, USA

2 Department of Marine, Earth, and Atmospheric Science, North Carolina State University, Campus Box 8208,

Raleigh, NC, 27695, USA

${ }^{3}$ Department of Civil, Construction, and Environmental Engineering, North Carolina State University, Campus Box 7908, Raleigh, NC, 27695, USA
} 
continuous line at the high resolution of the input DEM, providing results at the scale needed for local management, in contrast to the USGS approach, which is designed for continental scale vulnerability assessment. The method also allows for the storm impact scale to be solved and visualized in a highresolution raster format (Hardin et al. 2012). Finally, the least cost path approach solves for an optimized high-elevation path in locations where dunes are degraded or non-existent. This information is valuable because it is these locations that are particularly vulnerable to overwash and inundation.

In addition to topographic parameters, computation of the storm impact scale requires the storminduced extreme high water elevation. Sallenger (2000), Stockdon et al. (2007), Stockdon and Thompson (2007a,b) estimated the wave setup and runup for previous storms using empirical parameterizations, e.g., Holman 1986. These models were designed for use with natural beaches and therefore do not apply to sound-side forcing, as was the case with Irene. However, as Irene passed, the sound-side flooding left a line of debris (or a wrack line) at the edge of the high water. Therefore, in this work the elevation of the wrack line (determined through post-storm aerial photography and airborne LiDAR) was used as a proxy to the elevation of the extreme high water.

With the required topographic parameters and high water elevation, the vulnerability of the preIrene landscape is presented. Combined with the assessed vulnerability to Isabel in 2003, a history of vulnerability of the study site was constructed. High-resolution visualizations of the pre-storm topographies suggest that the formation of the breach was a function of the pre-storm dune field, which had been severely degraded by past storms.

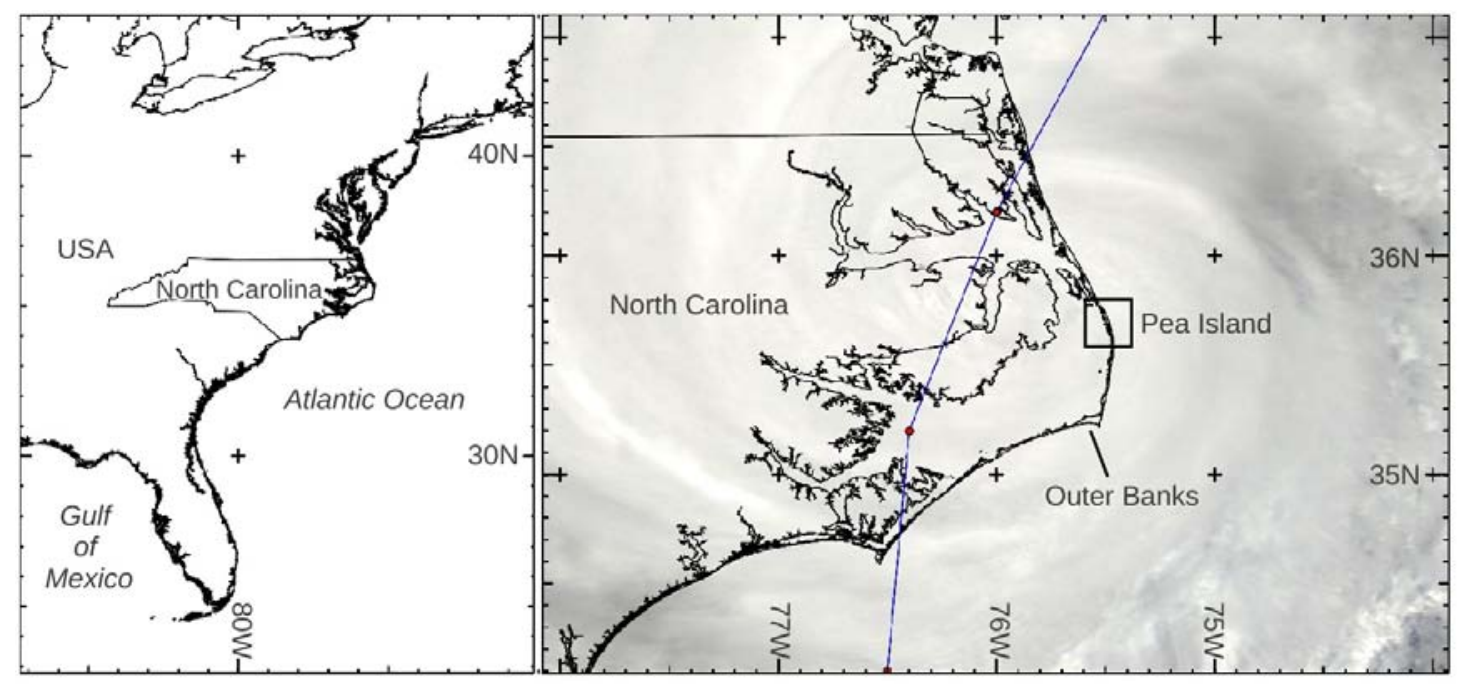

Figure 1. Location of the Outer Banks of North Carolina. The path of Hurricane Irene (National Weather Service, 2012) and extent as captured by MODIS (NASA FIRMS, 2012) on August 27th, 2011 are also shown.

\section{STUDY SITE}

The study site is the Pea Island National Wildlife Refuge (PINWR), which extends approximately $19 \mathrm{~km}$ from Oregon Inlet to the village of Rodanthe. The PINWR is undeveloped with the exception of North Carolina Highway NC12 and three small structures owned by the U.S. Fish and Wildlife Service.

Between NC12 and the shoreline, there resides a coastal dune system. The dune was constructed in the 1930s by the National Park Service to protect the Outer Banks from erosive hurricanes and winter storms (Birkemeier et al. 1984). The dunes were maintained up until the 1970s, when the dunes were left to evolve via natural processes whenever possible. Despite discontinued maintenance, the dunes still offer a level of protection to much of the island from storms and hurricanes.

However, in the PINWR, the dunes have failed to provide adequate protection multiple times in recent history, resulting in storm-damage to highway NC12. In 2003, Hurricane Isabel made landfall near Cape Lookout (approximately $50 \mathrm{~km}$ south of the PINWR) and continued to travel inland to the northwest. Isabel opened an inlet between the towns of Frisco and Hatteras, and caused widespread overwashing within the PINWR. The study site was again notably impacted in 2009 by the nor'easter that came to be known as the Veteran's Day Storm. The Veteran's Day Storm originated from Hurricane 
Ida, and its intensity and duration extensively degraded the protective dune system. Most recently, in August of 2011, Hurricane Irene opened multiple small breaches including the Pea Island breach.
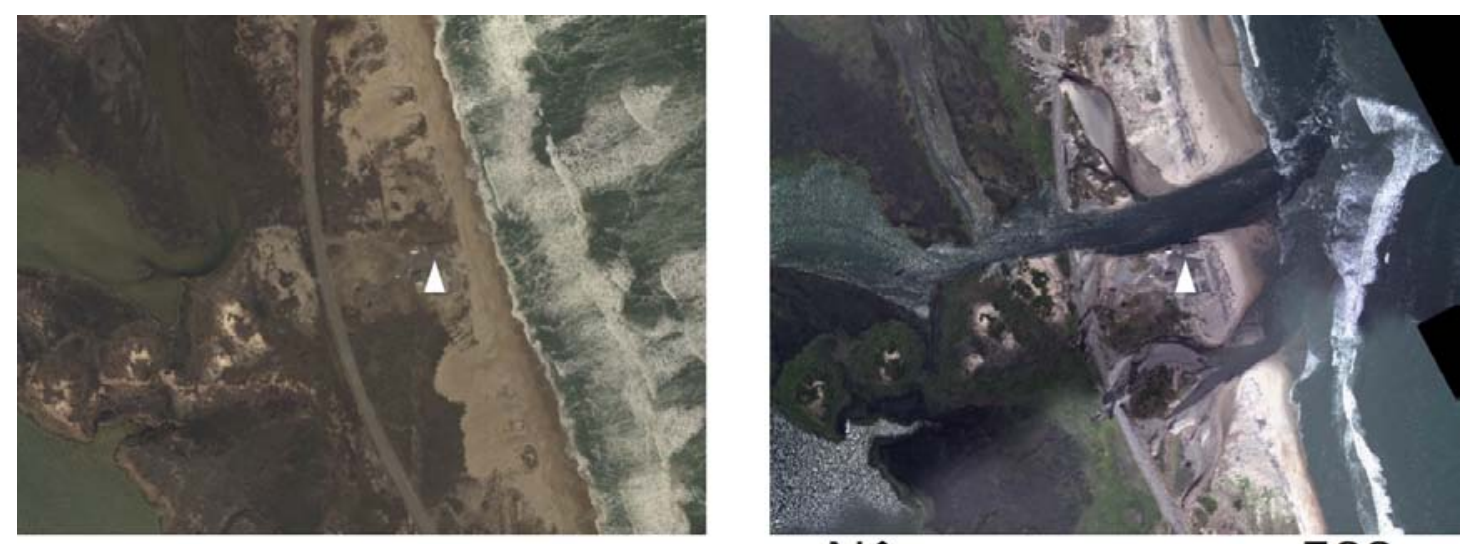

Ni

Figure 2. Location (lat 35:41, lon -75.29) of the Pea Island breach in 2008 (left) and in 2011 (right). The breach is located in the Pea Island National Wildlife Refuge, Outer Banks, NC.

\section{METHODOLOGY}

\section{LiDAR Data}

The Outer Banks (including the PINWR) have been surveyed by LiDAR on a near-annual basis since 1996, providing NC researchers with a rich time series of high-resolution topographic data. This time series has captured the response of the landscape to the most notable storms including Hurricane Isabel, the Veteran's Day Storm, and Hurricane Irene.

LiDAR has gained popularity as a mapping technology, and its advantages for mapping coastal topography are well demonstrated (Mitasova et al. 2004, Sallenger Jr et al. 2003, Shrestha et al. 2005, White and Wang 2003). The LiDAR data used in this study were downloaded from the Digital Coast a National Oceanic and Atmospheric Administration (NOAA) data distribution website (NOAACSC, 2012). Sampling densities of the available LiDAR data range from 0.1 to 8 points per square meter. On flat terrain the published horizontal accuracy is better than $2 \mathrm{~m}$ and the vertical accuracy is 0.12 to 0.20 $\mathrm{m}$.

It should be noted that some LiDAR missions were flown specifically to capture pre and post-storm topographies (e.g., the pre and post-Hurricane Isabel missions were both flown within days of Isabel making landfall). Other missions were flown only to capture the post-storm topography. In these cases, the previous LiDAR dataset was assumed to accurately represent the pre-storm topography (e.g., the mission prior to Irene in 2011 was flown to capture the post-Veteran's Day topography in 2009, and data from this mission was taken to represent the pre-Irene topography).

\section{LiDAR Aquisition and Processing}

All data (with the exception of the 2003 pre and post-Hurricane Isabel datasets) were downloaded in the North Carolina State Plane coordinate system relative to North American Vertical Datum 1988 in units of meters. The data collected before and after Isabel were provided by the USGS in the latitude/longitude geographic coordinate system and converted to the North Carolina State Plane coordinate system using GRASS GIS (GRASS Development Team, 2010).

LiDAR point clouds were interpolated into $0.5 \mathrm{~m}$ resolution DEMs using regularized spline with tension (Mitasova et al. 2005). The $0.5 \mathrm{~m}$ resolution was chosen to ensure adequate representation of salient features such as dune scarps and blowouts.

Once interpolated, systematic errors in the LiDAR datasets were identified and corrected. Systematic errors were identified by comparing the LiDAR datasets with high accuracy geodetic benchmarks that were measured by the NC Department of transportation along the centerline of highway NC12. For each LiDAR dataset, elevation differences between the benchmarks and LiDAR were computed. The median difference was used to measure systematic error. The systematic error was assumed to be spatially constant and was corrected by shifting the LiDAR so that the median difference 
became zero. Median and mean differences were comparable, but the median was used due to its low sensitivity to outliers. The root mean squared error among the LiDAR datasets was $10.5 \mathrm{~cm}$ (Hardin et al. 2011).

\section{Vulnerability Assessment}

In this work, vulnerability of a topography to a given storm is assessed by computing the USGS storm impact scale. The storm impact scale is solved by comparing the combined elevation of tide, surge, setup with and without runup to the elevation of the pre-storm dune toe and dune ridge. To solve for the vulnerability to Isabel, the elevation of storm surge and tide were modeled using ADCIRC (Luettich et al. 1992), and because Isabel caused ocean-side forcing, setup and runup were estimated using the empirical models developed by Holman (1986). Locations where the combined elevation of tide, surge, setup, and runup exceeded the pre-Isabel dune ridge were predicted to be vulnerable to overwash.

The USGS storm impact scale in its current form is not well suited to assess vulnerability to Hurricane Irene. This is because the storm impact scale was designed to assess vulnerability to oceanside storms and Irene was a sound-side event. Specifically, the concepts of wave runup, wave setup, and the dune toe, which underpin the storm impact scale, are ocean-front in nature: a dune toe is defined by Hallermeier and Rhodes (1988) as "the seaward point on the steep duneface," and wave setup and runup became negligible during Hurricane Irene as waves were damped out by vegetation, structures, and debris.

Consequently, the dune ridge and the extreme high water are the remaining topographic and storm parameters that are indicative of sound-side storm vulnerability. Therefore, in this work, vulnerability to Irene was predicted as being where the local extreme high water exceeded the pre-Irene dune ridge. Because debris was deposited at the edge of the high water during Irene, the wrack line elevation was used as a proxy to the extreme high water elevation.

The dune ridge and wrack line are three-dimensional, complex linear features that are not congruent - making their comparison nontrivial. Once the elevation of the wrackline had been determined, a surface representing the high water elevation was generated using inverse distance weighted interpolation, and this surface was then compared to the dune ridge. Locations where the high water elevation exceeded the pre-Irene dune ridge were predicted to be vulnerable to Hurricane Irene.

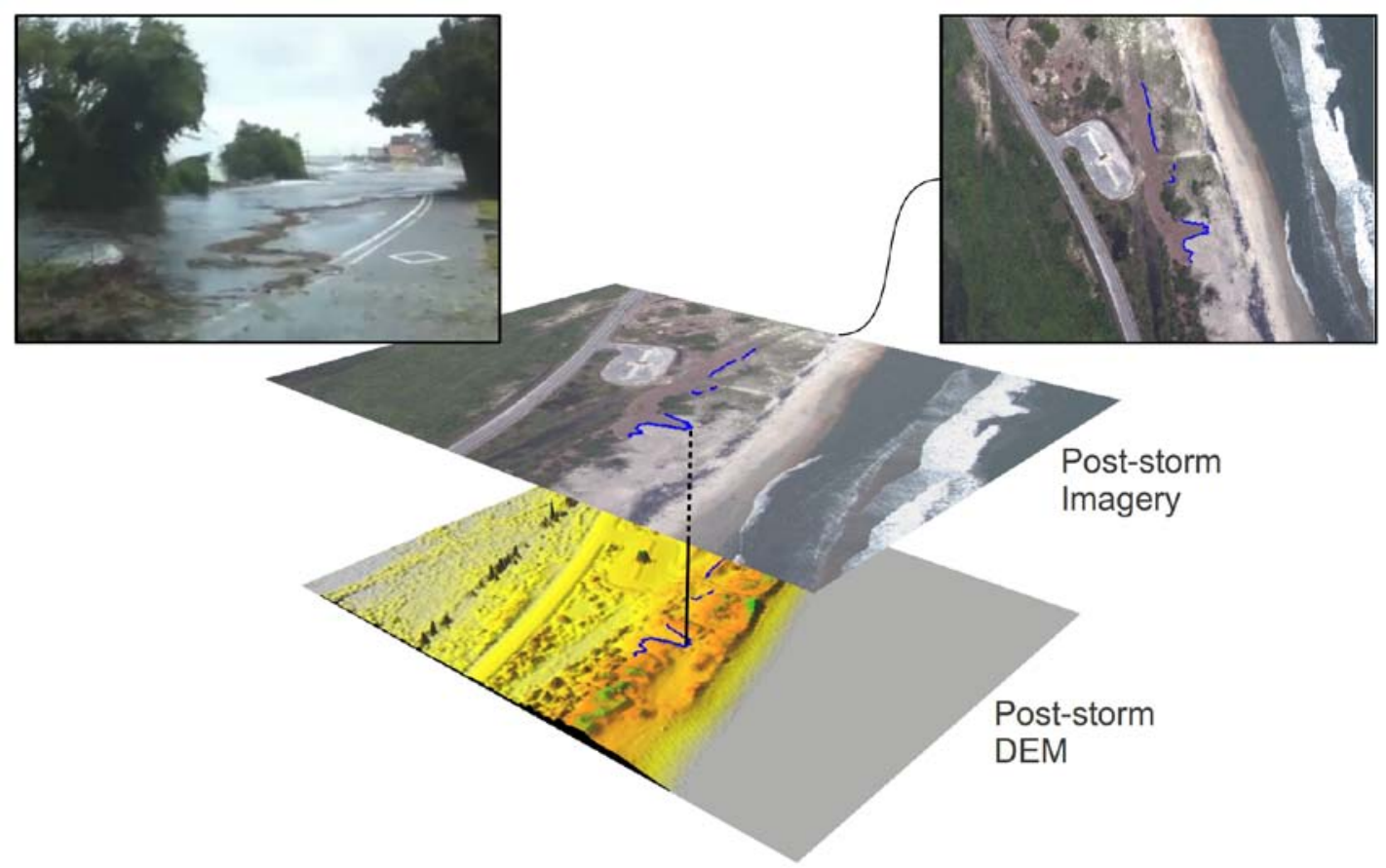

Figure 3. Example of the wrack line deposited on the sound side of the Outer Banks during Hurricane Irene, and illustration of the method to determine the wrack line elevation through digitization of post-storm imagery and sampling of the post-storm DEM. 


\section{Wrack Line Extraction}

Wrack lines have been measured in the field and used as proxies to high water levels in past studies, (e.g., Bush et al. 1996). Following the work of Clinch et al. (2012), a remote sensing-based approach was used to determine the location and elevation of the wrack line. In this approach, the planar location of the wrack line was manually digitized from post-storm aerial photography. Then, the elevation of the wrack line was determined by sampling the post-storm DEM (Figure 3).

Because wrack can be caught by vegetation, wrack lines were extracted only in minimally vegetated areas. Additionally, in areas where multiple wrack lines existed, those that were positioned closest to the dunes were extracted to accurately represent the highest elevation of water.

\section{Dune Ridge Extraction}

Dune ridges were then extracted from the DEMs using a least coast path approach (Hardin et al. 2012). In the least coast path approach, the continuous dune ridge is approximated by the least cost path connecting two points that are manually digitized at opposite ends of the studied dune ridge. The least cost path is computed for a cost surface that is an inverse function of the elevation. To this end, the path along the high-elevation dune ridge yields the least cost.

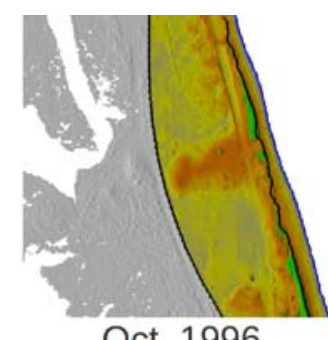

Oct. 1996

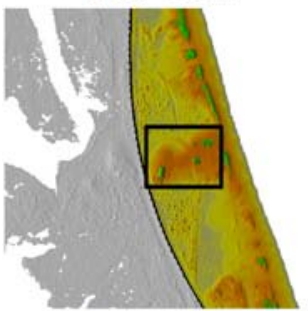

Mar. 2008
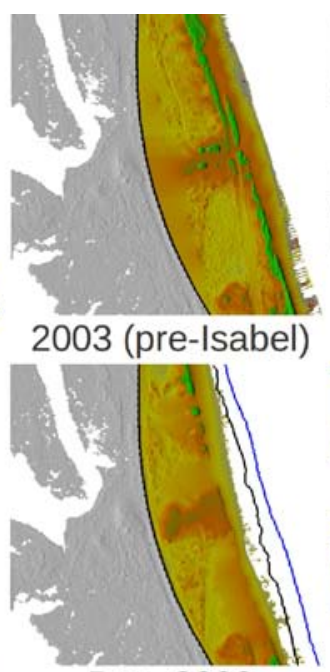

Dec. 2009

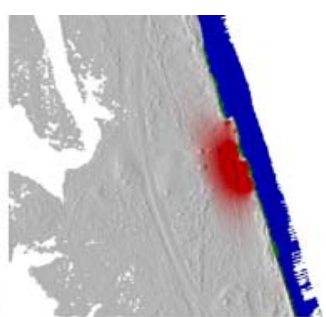

Isabel Impact

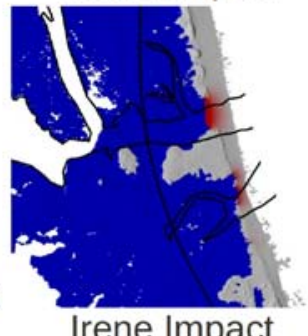

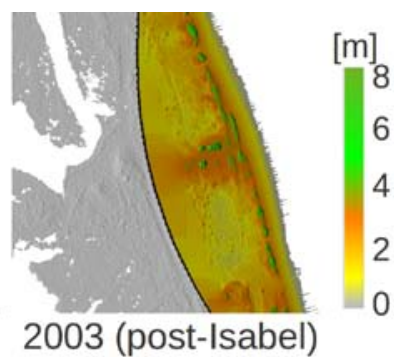
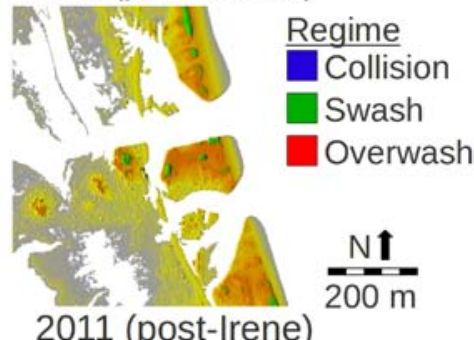

Figure 4. DEM snapshots of the dynamic landscape surrounding the new Pea Island breach. The locations of the 1996 dune crest (black) and shoreline (blue) are superimposed on the 2009 DEM to show the dramatic recession of the shoreline. The erosion regime predicted by the storm impact scale of Hurricanes Isabel and Irene are also shown. The outline of the Pea Island breach is overlaid on the Irene vulnerability map. The box shows the PINWR facilities in the 2008 DEM.

\section{RESULTS}

\section{Dune Elevation Analysis}

DEM snapshots show the evolution of the terrain surrounding the Pea Island breach area (Figure 4). At the beginning of the study period, the area had a largely continuous, well-developed dune ridge. Multiple locations of overwash are apparent subsequent to Hurricane Isabel. By 2008 the dunes had been further degraded, plausibly owing to the Thanksgiving Day storm in November 2006. By 2009, the Veteran's Day Storm had flattened the remaining dunes surrounding the location of the future Pea Island breach. The degraded state of the 2009 topography is of particular importance because it represents the topography prior to Hurricane Irene.

In addition to dune height, the 1996 dune ridge and shoreline positions are superimposed on the 2009 DEM to show the dramatic recession of the shoreline. By 2009, the shoreline resided landward of the location of the dune ridge in 1996. 


\section{Wrack Line Analysis}

The wrack line elevation is shown in Figure 5a. It is shown on the backdrop of the pre-storm dune elevation to assist visual assessment of vulnerability. The mean wrack line elevation was $2.07 \mathrm{~m}$ relative to mean high water with a standard deviation of $0.38 \mathrm{~m}$.

The wrack line was not continuously digitized over the entire study area. This is because a visible wrack line was not always present, or wrack lines were not digitized because of the presence of excessive vegetation.

In addition to its discontinuity, the wrack line elevation varies. Small length-scale variations may originate from digitization error or topographic features that existed in the post-storm DEM that were not visible in the post-storm aerial photography. Larger-scale variations may be caused by the large variations in the back-barrier geomorphology along the PINWR, and the associated bathymetric and topographic steering of storm surge.

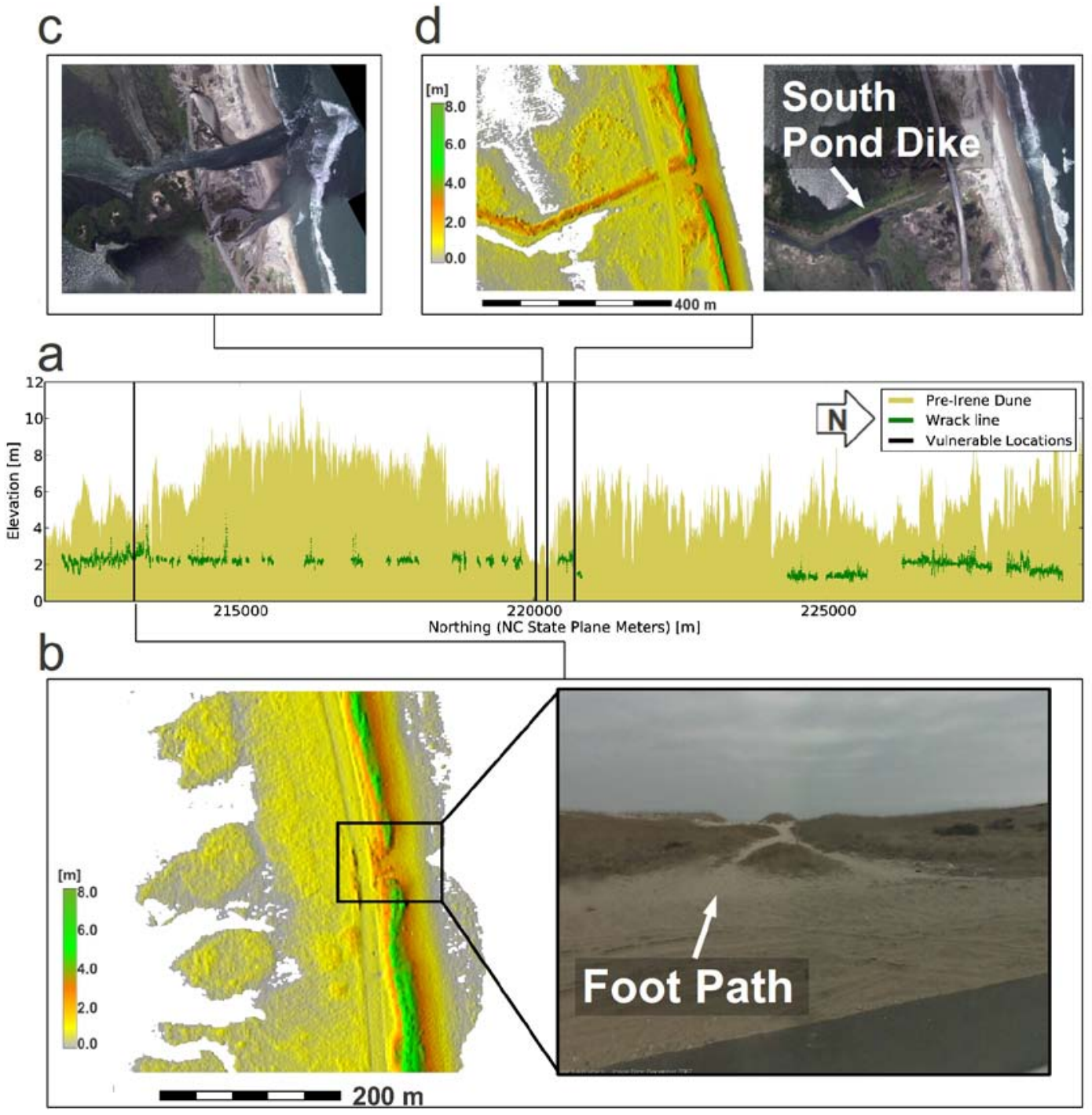

Figure 5. (a) Pre-Irene dune ridge elevation and Post-Irene wrack line elevations are shown. Four areas marked by the vertical lines were predicted to be vulnerable to Irene, two of which correspond to the two breach channels that formed during Irene. Insets of all four vulnerable locations are shown in insets a through $b$.

\section{Vulnerability Assessment}

To assess vulnerability of Pea Island to Hurricane Isabel, the elevation of the pre-Isabel dune ridge was compared to the elevation of the combined tide, storm surge, wave setup, and wave runup. The 
storm impact scale predicted that the area surrounding the future Pea Island breach was vulnerable to overwash during Isabel (Figure 4). The predicted vulnerability to overwash was substantiated by the post-storm aerial photography and DEM, in which overwash deposits are visible. No areas along Pea Island including the breach area were predicted to be vulnerable to inundation (Hardin et al. 2012).

Figure 5a shows that the elevation of the post-Irene wrack line locally exceeded the elevation of the pre-Irene dune ridge in four locations (Figures 5b-d). Two of the locations coincided with the two channels that formed in the Pea Island breach location (Figure $5 \mathrm{c}$ ). In the two vulnerable locations that did not correspond to the breach channel locations, overwash deposits were apparent in the aerial photography.

It should be stressed that this type of geospatial approach to vulnerability assessment cannot directly predict the geomorphological response that occurred. However, the topographic characteristics of the areas that did not breach may provide explanations as to why breach channels did not form.

In the southernmost vulnerable location (Figure 5b), a footpath was responsible for the drop in dune elevation below the elevation of the high water line. This location may not have experienced breaching simply because the small scale of the foot path did not allow for substantial scouring of the dune. Furthermore, the area lacks a back-barrier channel, which was present at the breach site and which may have been instrumental in promoting barrier island breaching during Irene. In the northernmost vulnerable location (Figure 5d), the permanent dike may have protected the island from breaching.
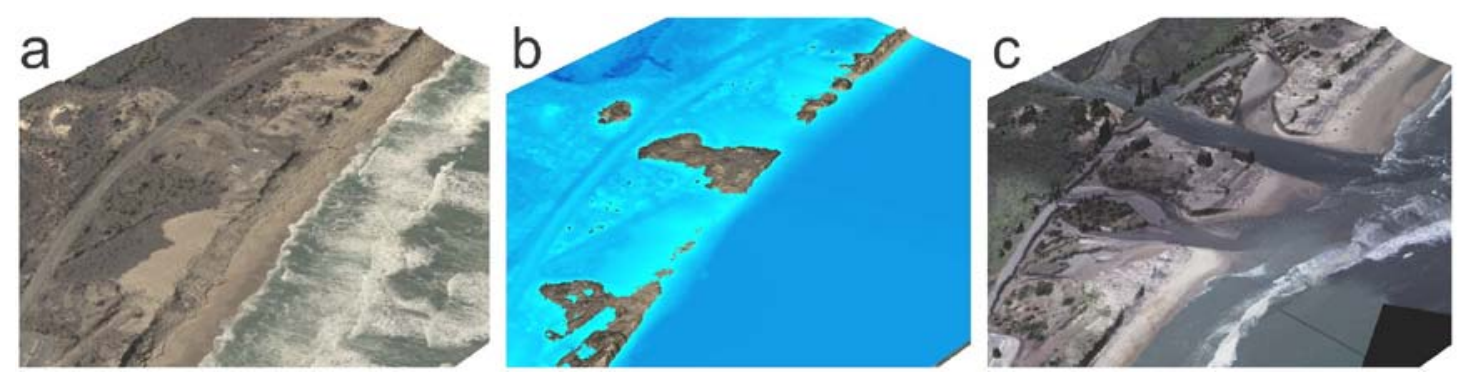

Figure 6. Three dimensional visualization of (a) the pre-Irene aerial photography draped over the pre-Irene DEM, (b) the high water surface (interpolated from the extracted wrack line) over the pre-storm DEM, and (c) the post-Irene aerial photography draped over the post-Irene DEM.

In addition to efficiently identifying potentially vulnerable locations, the raster format of the proposed methodology lends itself well to high-resolution, three-dimensional visualizations (Figure 6). By draping the pre and post-Irene aerial photography over the DEMs (Figure 6a and c respectively), and superimposing the high water elevation over the pre-Irene terrain (Figure 6b), Figure 6 illustrates the congruence of the breach channels and the locations where the elevation of the wrack line locally exceeded the pre-storm dune ridge.

\section{CONCLUSIONS}

A time series of LiDAR-derived DEMs were analyzed to study the geomorphological evolution of the area surrounding the Pea Island breach, as well as its implications for storm vulnerability. In the area surrounding the Pea Island breach, the time series of DEMs shows episodic decreases in dune height and continuity accompanied by landward migration of the shoreline. These morphological changes are associated with increasing vulnerability, and the island ultimately breached during Hurricane Irene in 2011.

To further investigate the implications of the terrain evolution to storm vulnerability, the USGS storm impact scale was used to assess vulnerability of the study site to Hurricanes Isabel in 2003 and Irene in 2011. Least cost path analysis was used was to extract the continuous dune ridge from the prestorm DEMs. Estimates of the extreme high water levels were compared to dune ridge elevation to assess vulnerability.

However, Hurricane Isabel and Hurricane Irene were characteristically different in that Isabel caused ocean-side forcing whereas Irene caused sound-side forcing. Therefore, to assess vulnerability to Isabel the elevation of storm surge and tide were modeled using ADCIRC and the wave setup and runup were estimated using an empirical parameterization. Alternatively, to assess vulnerability to Irene the 
wrack line - extracted from post-storm aerial photos and airborne LiDAR - was used as a proxy to the high water elevation.

During Isabel, multiple areas along Pea Island including the area immediately surrounding the future Pea Island breach were vulnerable to and did overwash. No areas were vulnerable to inundation. Wrack line analysis showed that prior to Irene, the study area was vulnerable to inundation in four locations, two of which correspond to the breach channel locations.

The evolution of the topography through the study period suggests that the Pea Island breach was not only caused by the unique characteristics of Hurricane Irene - but that previous storms had incrementally weakened the landscape to the point of collapse prior to Irene. This further suggests that the formation of the breach was a function of the pre-storm topography, and that management strategies could have been implemented to prevent its formation.

\section{REFERENCES}

Birkemeier, W., Dolan, R., and Fisher, N. 1984. The evolution of a barrier island: 1930-1980. Journal of the American Shore \& Beach Preservation Association, 52, 2-12.

Bush, D., Young, R., Webb, C., and Thieler, R. 1996. Soundside impacts of a northward tracking tropical cyclone: Hurricane Emily (31aug93). Journal of Coastal Research, 12, 229-239.

Clinch, A., Russ, E., Oliver, R., Mitasova, M., and Overton, M. 2012. Hurricane Irene and the Pea Island Breach: Pre-storm site characterization and storm surge estimation using geospatial technologies. Shore \& Beach, 80, 1-10.

Garcia-Mora, M., Gallego-Fernandez, J., Williams, A., and Garcia-Novo, F. 2001. A coastal dune vulnerability classifcation. A case study of the SW Iberian Peninsula. Journal of coastal research, 802-811.

GRASS Development Team, 2010. Geographic Resources Analysis Support System (GRASS GIS) Soft-ware. Open Source Geospatial Foundation, USA.

Hallermeier, R. and Rhodes, P. 1988. Generic treatment op dune erosion for 100-year event. Proceedings of the $21^{\text {st }}$ International Conference on Coastal Engineering.

Hardin, E., Kurum, M., Mitasova, H., and Overton, M. 2012. Least cost path extraction of topographic features for storm impact scale mapping. Journal of Coastal Research, 28, 970-978.

Hardin, E., Mitasova, H., and Overton, M. 2011. Quantifcation and Characterization of Terrain Evolution in the Outer Banks, N.C. In Proceedings of the Coastal Sediments `11, Miami, FL, 739753.

Holman, R. 1986. Extreme value statistics for wave run-up on a natural beach. Coastal Engineering, 9, 527-544.

Jimenez, J., Ciavola, P., Balouin, Y., Armaroli, C., Bosom, E., and Gervais, M. 2009. Geomorphic coastal vulnerability to storms in microtidal fetch-limited environments: Application to NW Mediterranean \& N Adriatic Seas. Journal of Coastal Research, SI56, 1641-1645.

Jin, Q. and Overton, M. 2011. Quantitative analysis of coastal dune erosion based on geomorphology features and model simulation. In Proceedings of the Coastal Sediments '11, Miami, FL, pages 1825-1840.

Judge, E., Overton, M., and Fisher, J. 2003. Vulnerability indicators for coastal dunes. Journal of Waterway, Port, Coastal, and Ocean Engineering. 129, 270-278.

Luettich,R., Westerink,J., and Schener, N. 1992. ADCIRC: An Advanced Three-Dimensional Circulation Model for Shelves, Coasts, and Estuaries. Report 1. Theory and Methodology of ADCIRC-2DDI and ADCIRC-3DL. Technical report, Vicksburg, Mississippi: Coastal Engineering Research Center. Technical Report ADA261608.

Mitasova, H., Drake, T., Bernstein, D., and Harmon, R. 2004. Quantifying rapid changes in coastal topography using modern mapping techniques and geographic information system. Environmental and Engineering Geoscience, 10, 1-11.

Mitasova, H., Mitas, L., and Harmon, R. 2005. Simultaneous spline approximation and topographic analysis for lidar elevation data in open-source GIS. IEEE Geoscience and Remote Sensing Letters, 2, 375-379.

NASA FIRMS. 2012. Modis active fire detections. data set. Available onhttp://earthdata.nasa.gov/firms.

National Weather Service. 2012. Hurricane irene advisory archive. http://www.nhc.noaa.gov/archive/2011/IRENE.shtml? 
NOAACSC. 2012. National Oceanic and Atmospheric Administration Coastal Services Center Coastal Lidar. http://www.csc.noaa.gov/digitalcoast/data/coastallidar/index.html Accessed 25 May 2012.

Sallenger, A. 2000. Storm impact scale for barrier island. Journal of Coastal Research, 16, 890-895.

Sallenger Jr, A., Krabill, W., Swift, R., Brock, J., List, J., Hansen, M., Holman, R., Manizade, S., Sontag, J., Meredith, A., et al. 2003. Evaluation of airborne topographic lidar for quantifying beach changes. Journal of Coastal Research, 19, 125-133.

Shrestha, R., Cartera, W., Sartoria, M., Luzuma, B., and Slatton, K. 2005. Airborne laser swath mapping: Quantifying changes in sandy beaches over time scales of weeks to years. ISPRS Journal of Photogrammetry \& Remote Sensing, 59, 222-232.

Stockdon, H., Sallenger, A., and Holman, R. 2007. A simple model for the spatially-variable coastal response to hurricanes. Marine Geology, 238, 1-20.

Stockdon, H. and Thompson, D. 2007a. Vulnerability of national park service beached to inundation during a direct hurricane landfall: Cape lookout national seashore. U.S. Geological Survey OpenFile Report 2007-1376.

Stockdon, H. and Thompson, D. 2007b. Vulnerability of national park service beached to inundation during a direct hurricane landfall: Fire island national park. U.S. Geological Survey Open File Report 2007-1389.

Stone, J., Overton, M., and Fisher, J. 1991. Options for North Carolina Coastal Highways Vulnerable to Long Term Erosion, prepared for the North Carolina Department of Transportation and the US Department of Transportation Federal Highway Administration.

White, S. andWang, Y. 2003. Utilizing DEMs derived from LIDAR data to analyze morphologic change in the North Carolina coastline. Remote Sensing of Environment, 85, 39-47. 